\title{
Etiología del síndrome febril prolongado en niños
}

\author{
M. SOLEDAD PEREDO G. ${ }^{1}$, TAMARA VIVIANI S. ${ }^{2,3}$, ANAMARÍA PEÑA D..$^{2,3}$ \\ 1. Residente de Pediatría, Pontificia Universidad Católica de Chile. \\ 2. Profesor Adjunto, Departamento de Pediatría, Pontificia Universidad Católica de Chile. \\ 3. Infectóloga, Unidad de Infectología Pediátrica, Hospital Dr. Sótero del Río.
}

\begin{abstract}
Etiology of Prolonged Fever in Children

Background: Prolonged fever (PF) is an uncommon entity in children, produced by diverse etiologies that differ according to geographic areas and national socioeconomical status. Objective: To determine etiologic diagnosis of PF in children from the southeast area of Santiago. Methods: A prospectivedescriptive study performed in 35 patients with PF, age between 6 months - 15 years, referred to the Pediatrics Infectious Diseases Unit of Hospital Sótero del Río during 2005 and 2006. Results: In 74\% of cases an etiologic diagnosis was established, predominantly infectious diseases $(68 \%)$ and rheumatologic disorders $(6 \%)$. The most frequent infections observed were Bartonella henselae $(17 \%)$, urinary tract infection (11\%) and Epstein Barr virus infection (5.7\%). Conclusions: PF in children from the southeast area of Santiago is caused by multiple etiologies, mainly infections with a high incidence of Bartonella henselae.
\end{abstract}

(Key words: Prolonged fever, children, Bartonella henselae).

Rev Chil Pediatr 2007; 78 (5): 472-476

\section{RESUMEN}

Introducción: El síndrome febril prolongado (SFP) es una patología infrecuente en niños, que incluye una amplia gama de etiologías que difieren según área geográfica y nivel socioeconómico del país. Objetivo: Determinar el diagnóstico etiológico específico de SFP en niños del sector sur-oriente de Santiago. Pacientes y Métodos: Se realizó un estudio descriptivo prospectivo en 35 pacientes con SFP, entre seis meses a quince años de edad, derivados a la Unidad de Infectología Pediátrica del Hospital Dr. Sótero del Río durante los años 2005 y 2006. Resultados: Se obtuvo diagnóstico etiológico definitivo en $74 \%$ de los pacientes. Las etiologías más frecuentes fueron infecciosas $(68 \%)$ o reumatológicas $(6 \%)$. Las etiologías específicas más frecuentes fueron Bartonella henselae (17\%), infección del tracto urinario (11\%) e infección por virus Epstein Barr (5,7\%). Conclusión: El SFP en el grupo de niños estudiados del sector suroriente de Santiago se debe a múltiples etiologías, principalmente de origen infeccioso, destacando Bartonella henselae.

(Palabras clave: Síndrome febril prolongado, niños, Bartonella henselae).

Rev Chil Pediatr 2007; 78 (5): 472-476

Trabajo recibido el 4 de mayo de 2007, devuelto para corregir el 27 de agosto de 2007, segunda versión el 12 de septiembre de 2007, aceptado para publicación el 1 de octubre de 2007.

Correspondencia a:

Dra. M. Soledad Peredo G.

E-mail:mperedo@puc.cl 


\section{Introducción}

El síndrome febril prolongado (SFP) en niños, si bien no es una patología frecuente, constituye aún hoy en día un desafío diagnóstico y una causa de ansiedad importante para padres y médicos tratantes, llevando muchas veces a incurrir en gastos innecesarios y hospitalizaciones prolongadas. Existen escasos reportes respecto a este tema en la literatura tanto nacional como internacional y hay falta de consenso en cuanto a su definición, además de una importante variabilidad de las etiologías descritas según lugar geográfico y nivel de desarrollo del país ${ }^{1-3}$. Todo esto dificulta el estudio apropiado y diagnóstico oportuno de esta patología.

Dentro de las etiologías reportadas, la más frecuente es la infecciosa, seguida de la neoplásica y la reumatológica ${ }^{1,4}$. Las distintas series concuerdan en que el diagnóstico final corresponde en general a etiologías relativamente habituales de presentación atípica, destacando en forma emergente la infección por virus Epstein-Barr y Bartonella henselae ${ }^{5-7}$. A pesar del estudio diagnóstico exhaustivo y de los avances en medicina en cuanto a exámenes de laboratorio e imágenes, entre un 15 y un $30 \%$ de los casos quedan sin diagnóstico etiológico preciso $^{1,4,7}$.

En este contexto se diseñó este estudio descriptivo con el fin de conocer las distintas etiologías del SFP en una población pediátrica del área sur-oriente de Santiago. Secundariamente se desea describir algunas formas de presentación atípicas de enfermedades frecuentes y así poder dirigir mejor el estudio de esta patología.

\section{Pacientes y Métodos}

Se realizó un estudio descriptivo prospectivo en pacientes pediátricos entre seis semanas y quince años de edad derivados a la Unidad de Infectología Pediátrica Ambulatoria del Hospital Dr. Sótero del Río (HSR) durante el período comprendido entre septiembre 2005 y diciembre 2006, en quienes se realizó el diagnóstico de SFP. Se definió como SFP la presencia de fiebre durante 7 o más días en niños de 6 semanas a 4 años y al menos 10 días en niños mayores de 4 años, en base a diferentes publicaciones nacionales y extranjeras y a la experiencia clínica previa de este centro ${ }^{5,6,8,9}$. Se consideró fiebre la presencia de temperatura superior a $38^{\circ} \mathrm{C}$ rectal o $37,5^{\circ} \mathrm{C}$ axilar, presente todos los días en al menos una toma diaria. Para ingresar al estudio los pacientes no debían tener diagnóstico etiológico específico al momento de ser derivados a la unidad. Se excluyeron del estudio aquellos pacientes portadores de inmunodeficiencia congénita o adquirida, patología neoplásica y aquellos con historia de síndromes febriles periódicos.

Se realizó una ficha de seguimiento de todos aquellos pacientes que cumplían con los criterios de ingreso al estudio, completando un cuestionario de antecedentes, examen físico exhaustivo y estudio de laboratorio inicial. Según la evolución y sospecha clínica se realizaron nuevos estudios y controles seriados hasta obtener un diagnóstico definitivo o la resolución total de la fiebre (figura 1).

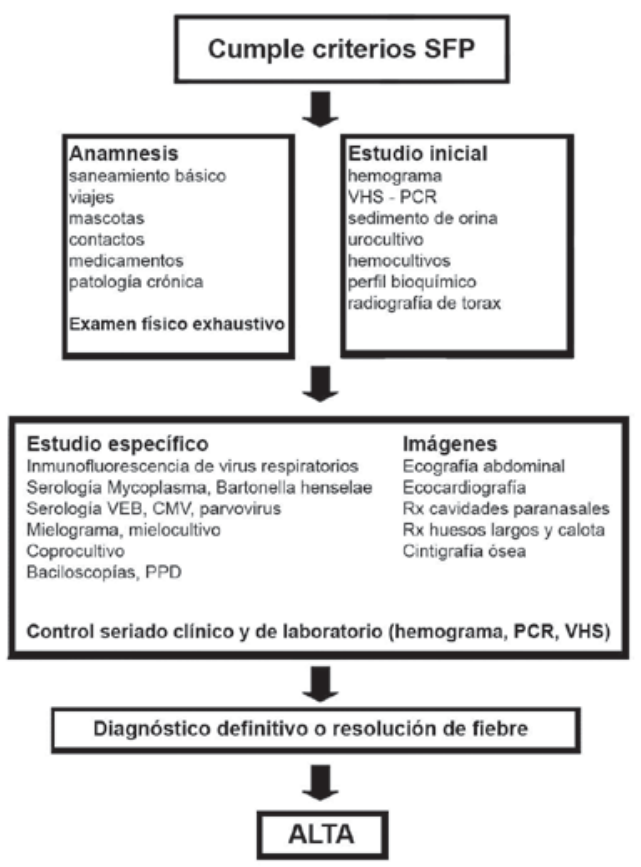

Figura 1. 
Los estudios serológicos IgM VCA VEB e IgM Mycoplasma, así como IgG Bartonella henselae fueron enviados y procesados en el laboratorio de microbiología y laboratorio del Centro de Investigaciones Médicas de la Pontificia Universidad Católica, respectivamente.

\section{Resultados}

Se estudiaron 35 pacientes que cumplían con los criterios descritos, el rango de edad fue de 6 meses a 15 años ( $\bar{x}=5,0$ años), la distribución por género fue $42,9 \%$ femenino y $57,1 \%$ masculino. La duración de la fiebre varió entre 7 y 22 días $(\overline{\mathrm{x}}=11,8$ días $)$. Se obtuvo diagnóstico etiológico preciso en $74 \%$ de los pacientes estudiados. Dentro de las etiologías encontradas la más frecuente fue la infecciosa, en 24 pacientes $(68 \%)$, seguida de la reumatológica en 2 pacientes $(6 \%)$, sin ningún caso de etiología neoplásica. En 9 pacientes $(26 \%)$ no fue posible determinar una etiología específica.

En la tabla 1 se presentan las distintas etiologías específicas encontradas, destacando la infección por Bartonella henselae como la más frecuente, seguida de la infección del tracto

Tabla 1. Diagnóstico etiológico específico de SFP

\begin{tabular}{lrr}
\hline Diagnóstico & $\mathbf{n}$ & \% \\
\hline Bartonella henselae & 6 & $(17,1)$ \\
Infección tracto urinario & 4 & $(11,4)$ \\
Virus Epstein Barr & 2 & $(5,7)$ \\
Neumonía & 2 & $(5,7)$ \\
Fiebre tifoidea & 1 & $(2,9)$ \\
Influenza A & 1 & $(2,9)$ \\
Parainfluenza 3 & 1 & $(2,9)$ \\
Virus respiratorio sincicial & 1 & $(2,9)$ \\
Enterovirus & 1 & $(2,9)$ \\
Micoplasma pn & 1 & $(2,9)$ \\
Sinusitis & 1 & $(2,9)$ \\
Otitis media aguda & 1 & $(2,9)$ \\
Escarlatina (SGA) & 1 & $(2,9)$ \\
Endocarditis bacteriana & 1 & $(2,9)$ \\
Enfermedad de Kawasaki & 1 & $(2,9)$ \\
Artritis reumatoídea juvenil & 1 & $(2,9)$ \\
Sin diagnóstico definitivo & 9 & $(25,7)$ \\
\hline
\end{tabular}

urinario (ITU) y la infección por virus EpsteinBarr (VEB). Cabe destacar que de los pacientes que presentaron infección por Bartonella henselae, todos refirieron haber tenido contacto previo con gatos en la encuesta inicial. Asimismo, de todos los que refirieron contacto con gatos, un 66,6\% desarrolló finalmente infección por Bartonella henselae como causa de SFP. Respecto al cuadro clínico de estos pacientes, uno sólo se presentó como Enfermedad por Arañazo de Gato (EAG) característica con lesión de inoculación en el antebrazo; tres se presentaron como SFP con compromiso hepatoesplénico encontrado como hallazgo de la ecografía abdominal; y dos se presentaron como SFP aislado sin otras alteraciones. Todos ellos tuvieron serología positiva para $B$. henselae con títulos de anticuerpos IgG $>1: 256$.

De los pacientes con ITU, 3 fueron lactantes y se presentaron con SFP, sedimento urinario normal y cultivo de orina que mostró infección bacteriana; el cuarto fue un preescolar que presentó 15 leucocitos en el sedimento urinario y un cultivo de orina positivo, en ausencia de síntomas.

De los pacientes con diagnóstico de infección por VEB, ambos en edad escolar, ninguno se presentó como síndrome mononucleósico característico, destacando la ausencia de adenopatías y hepatoesplenomegalia al examen físico y ecográfico, siendo la etiología un hallazgo del estudio rutinario.

\section{Discusión}

Esta serie muestra la distribución de diagnósticos etiológicos del SFP en niños del área sur-oriente de Santiago derivados a la Unidad de Infectología Pediátrica del HSR. Concordantemente con la literatura publicada la etiología infecciosa sigue siendo la más relevante en nuestro centro, alcanzando dos tercios de los casos, sin embargo, dentro de las etiologías específicas encontradas existen ciertas diferencias $^{1-7}$. Entre las etiologías más frecuentes observadas en países en desarrollo persisten la tuberculosis, fiebre tifoidea, leishmaniasis y brucelosis ${ }^{4,5,7}$. Asimismo un estudio chileno de 1980 de Moya, Talesnik y Larco muestra la 
fiebre tifoídea como causa de fiebre prolongada en la mitad de los casos revisados ${ }^{9}$. Sin embargo, a diferencia de lo anterior en nuestra serie se presentó sólo un caso de fiebre tifoidea en forma aislada y ningún caso de tuberculosis ni de los otros agentes mencionados. Las etiologías más frecuentes encontradas en nuestro estudio -Bartonelosis, ITU e infección por VEB- son consistentes con reportes norteamericanos de la última década y nuevos reportes de países como Nigeria y Serbia y Montenegro ${ }^{1,5-7}$. Esto podría ser un reflejo de transición epidemiológica que está experimentando nuestro país, especialmente al comparar los resultados obtenidos con los del mismo centro asistencial hace más de 25 años ${ }^{9}$. Llama la atención que la presentación de estas etiologías fue atípica en la mayoría de los casos, no permitiendo el diagnóstico temprano por sospecha clínica, sino presentándose como SFP. La presentación atípica de Bartonella henselae como fiebre prolongada, con o sin compromiso hepatoesplénico, ya había sido reportada por algunas series nacionales e internacionales ${ }^{1,10,11}$, sin embargo, la frecuencia de presentación como causa de SFP fue inusualmente alta en nuestro estudio. Existe un estudio reciente de Ferrés y colaboradores que demostró la alta prevalencia de anticuerpos contra $B$. henselae en población pediátrica de nuestro país, así como en población con riesgo ocupacional (veterinarios y auxiliares técnicos), lo que sugiere una alta tasa de exposición a este agente, por lo que no se puede descartar que la serología positiva en algunos de nuestros pacientes con SFP haya sido adquirida previamente ${ }^{11}$. Sin embargo, dada la presencia de síntomas en los casos descritos y la serología positiva en títulos elevados $(>1$ : 256), en ausencia de otra etiología identificable, lo más probable es que se trate efectivamente de infección aguda por Bartonella henselae y sea ésta la causa del síndrome febril. Este mismo autor demostró la alta prevalencia de serología positiva para Bartonella en gatos y su importancia como reservorio en tres ciudades distintas del país, ratificando la relevancia del antecedente de contacto previo con gatos, especialmente mordedura o $\operatorname{arañazos}^{12}$. Esto coincide con los casos descritos en nuestra serie, en que todos los pacientes afectados refirieron haber tenido contacto previo con gatos.

Respecto a la ITU, ésta sigue siendo una causa importante de SFP especialmente en lactantes y preescolares, edad en que es característica la ausencia de síntomas, lo cual dificulta la sospecha clínica, por lo que debe ser considerada dentro de las causas de SFP en niños pequeños, aun en presencia de un sedimento de orina normal.

En lo referente a infección por VEB, el diagnóstico se realiza habitualmente en forma precoz, dado los hallazgos característicos de esta patología, y sólo se prolongan aquellos casos con ausencia de síndrome mononucleósico clásico, más frecuente a edades menores, lo cual explicaría la presentación clínica de nuestros dos pacientes.

Respecto a la etiología neoplásica, mencionada en otras series, llama la atención la ausencia de ésta en nuestro estudio. Esto se debe probablemente al número pequeño de pacientes incluidos en nuestra serie. En años anteriores, en datos no publicados de este mismo grupo se han encontrado casos de SFP de etiología neoplásica en el mismo recinto hospitalario.

Respecto a la etiología reumatológica, ésta coincide con las otras series, las cuales comunican también la presencia de enfermedad de Kawasaki y artritis reumatoídea juvenil (ARJ) dentro de las causas de SFP en niños ${ }^{5-7}$.

En cuanto al número de casos sin diagnóstico etiológico definitivo, las cifras son variables en las series publicadas, y la magnitud relativamente elevada de nuestro porcentaje podría deberse a la limitación de recursos disponibles para estudios más específicos en nuestro centro y a que éstos se realizan sólo frente a sospecha clínica fundada. Cabe destacar que todos los pacientes sin diagnóstico definitivo fueron seguidos hasta la resolución de la fiebre y se encontraban en buenas condiciones al momento del alta de la unidad.

De este modo, una vez conocidas las etiologías más frecuentes de SFP en nuestro centro hospitalario, podemos dirigir en forma racional el enfrentamiento del SFP en niños, dentro del cual destaca una vez más la importancia de la anamnesis como parte fundamental 
del estudio, preguntar específicamente por contacto con mascotas, en especial gatos; así como un examen físico cuidadoso y repetido en busca de nuevos hallazgos y estudio de laboratorio e imágenes dirigido. En este contexto en nuestro centro hospitalario recomendamos tener en consideración como causa de SFP la infección por Bartonella henselae y virus de Epstein Barr, aún en ausencia de su presentación clínica típica, dada su frecuencia relativa en nuestra serie.

\section{Referencias}

1.- Jacobs R, Schutze G: Bartonella henselae as a Cause of Prolonged Fever and Fever of Unknown Origin in Children. Clin Infect Dis 1998; 26: 80-4.

2.- Tabak F, Mert A, Celik AD, et al: Fever of unknown origin in Turkey. Infection 2003; 31: 417-20.

3.- Baicus C, Bolosiu HD, Tanasescu C, Baicus A: Fever of unknown origin: Etiology. A prospective multicenter study of 164 patients. Rev Med Chir Soc Med Nat Iasi 2003; 107: 545-50.

4.- Çiftçi E, Ince E, Dogru Ü: Pyrexia of unknown origin in children: a review of 102 patients from Turkey. Ann Trop Paediatr: International Child Health 2003; 23: 259-63.
5.- Akpede GO, Akenzua GI: Management of children with prolonged fever of unknown origin and difficulties in the management of fever of unknown origin in children in developing countries. Paediatr Drugs 2001; 3: 247-62.

6.- Gartner JC: Fever of unknown origin. Adv Pediatr Infect Dis 1992; 7: 1-24.

7.- Pasic S, Minic A, Djuric P, et al: Fever of unknown origin in 185 paediatric patients: A single-centre experience. Acta Pædiatr 2006; 95: 463-66.

8.- Moya F, Talesnik E, Larco R: Fiebre prolongada en preescolares y escolares. Rev Chil Pediatr 1980; 51: 174-8.

9.- Tsujino K, Tsukahara M, Tsuneoka H, et al: Clinical implication of prolonged fever in children with cat scratch disease. J Infect Chemother 2004; 10: 227 33.

10.- Navarrete $M$, Täger $M$, Wenzel MS, Podestá L, Pincheira M, Zaror L: Formas atípicas de enfermedad por arañazo de gato, Valdivia. Rev Chil Infect 2003; 20: 257-61.

11.- Ferrés M, Abarca K, Prado P, Montecinos L, Navarrete M, Vial P: Prevalencia de anticuerpos contra Bartonella henselae en niños, en adolescentes y en una población de riesgo ocupacional en Chile. Rev Med Chil 2006; 134: 863-7.

12.- Ferrés M, Abarca K, Godoy $P$, et al: Presencia de Bartonella henselae en gatos: cuantificación del reservorio natural y riesgo de exposición humana de esta zoonosis en Chile. Rev Méd Chile 2005; 133: 1465-71. 